
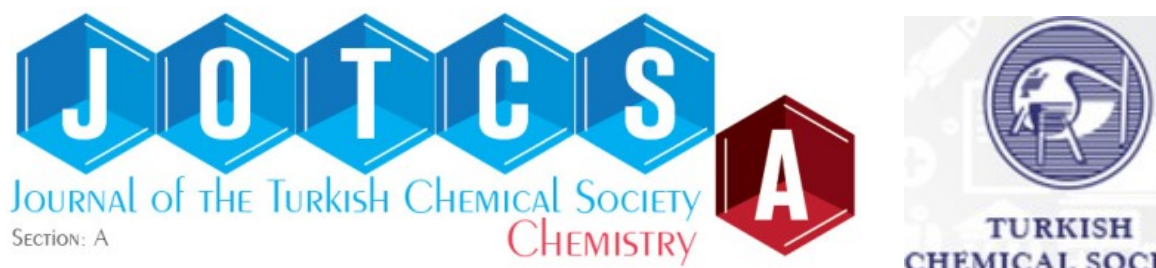

TURKISH

CHEMICAL SOCIETY

\title{
Hirshfeld Surface Analysis, Interaction Energy Calculations of Metal (II) 4-Cyanobenzoate with Nicotinamide / N,N'-Diethylnicotinamide Complexes
}

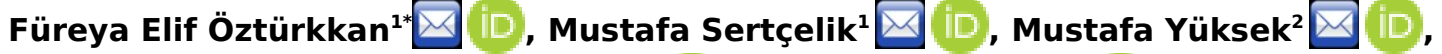 \\ Hacali Necefoğlu ${ }^{3} \otimes$ (iD), Tuncer Hökelek ${ }^{4}$ \\ ${ }^{1 *}$ Kafkas University, Engineering and Architecture Faculty, Department of Chemical Engineering, Kars, \\ Turkey. \\ ${ }^{2}$ Iskenderun Technical University, Faculty of Engineering and Natural Sciences, Department of Electrical and \\ Electronics Engineering, Iskenderun, Hatay, Turkey. \\ ${ }^{3}$ Kafkas University, Art and Science Faculty, Department of Chemistry, Kars, Turkey. \\ ${ }^{4}$ Hacettepe University, Faculty of Science, Department of Physics, Ankara, Turkey.
}

Abstract: Hirshfeld surface analysis, a suitable tool for investigating intermolecular interactions, has been widely used in crystallography in recent years. A breakdown of related fingerprint graphics is presented as a color chart, allowing a quantitative analysis of intermolecular interaction types. In this study, the intermolecular interactions of diaqua-bis(4-cyanobenzoato- $k O$ )bis(nicotinamide- $\left.k N^{1}\right)$ cobalt(II) (I), diaquabis(4-cyanobenzoato- $K O$ ) bis(nicotinamide- $\left.K N^{N}\right) \operatorname{copper}(I I) \quad$ (II), diaquabis(4-cyanobenzoato$\kappa O$ )bis(nicotinamide- $\left.K N^{1}\right)$ nickel(II) $\quad\left(\right.$ III), $\quad$ triaqua(4-cyanobenzoato- $\kappa^{2} O, O$ ) (nicotinamide- $k M$ )zinc(II) cyanobenzoate (IV), diaquabis(4-cyanobenzoato- $K O)$ bis $\left(N, N^{\prime}\right.$-diethylnicotinamide- $\left.K N\right)$ cadmium(II) (V) diaquabis(4-cyanobenzoato- $K O)$ bis $\left(N, N^{\prime}\right.$-diethylnicotinamide- $\left.K N\right)$ zinc(II) (VI) and catena-poly[laquabis(4cyanobenzoato- $K O$ ) copper(II)]- $\mu-N, N^{\prime}$-diethylnicotinamide- $\left.\kappa^{2} N^{1}: O\right]$ (VII) complexes, crystal structures were previously determined and investigated by using Hirshfeld surface analysis via CrystalExplorer Program Version 17.5. In addition, the intermolecular interaction energies of the complexes were calculated using CEHF/3-21G and CE-B3LYP/6-31G (d,p) energy models that involved in CrystalExplorer (CE) software. Related to the obtained Hirshfeld surface analysis results, $\mathrm{H} \cdots \mathrm{H}, \mathrm{H} \cdots \mathrm{C} / \mathrm{C} \cdots \mathrm{H}, \mathrm{H} \cdots \mathrm{O} / \mathrm{O} \cdots \mathrm{H}, \mathrm{H} \cdots \mathrm{N} / \mathrm{N} \cdots \mathrm{H}, \mathrm{C} \cdots \mathrm{C}, \mathrm{C} \cdots \mathrm{N} / \mathrm{N} \cdots \mathrm{C}$ and $\mathrm{C} \cdots$ $\mathrm{O} / \mathrm{O} \cdots \mathrm{C}$ constitute the intermolecular interactions of the complexes. Additionally, $\mathrm{N} \cdots \mathrm{O} / \mathrm{O} \cdots \mathrm{N}$ and $\mathrm{N} \cdots \mathrm{N}$ interactions only in I, II, III, IV and VII complexes, $\mathrm{H} \cdots \mathrm{Cu} / \mathrm{Cu} \cdots \mathrm{H}, \mathrm{O} \cdots \mathrm{Cu} / \mathrm{Cu} \cdots \mathrm{O}$ only in complexes II and $\mathbf{V I I}$ and $\mathrm{O}$ - $\mathrm{O}$ interactions only in complexes II, $\mathbf{V}$ and $\mathbf{V I}$ were also found. The most significant interactions of all of the complexes were found as the $\mathrm{H} \cdots \mathrm{H}$ interactions. These results support the existence of $\pi-\pi$ interactions between benzene and pyridine rings and medium strength hydrogen bonds which contribute to the stability of the crystal packing of the complexes that are determined by single crystal X-ray diffraction method. Depending on the intermolecular interactions and the energy-framework analysis the $\mathrm{O}-\mathrm{H} \cdots \mathrm{O}$ and $\mathrm{N}-\mathrm{H} \cdots \mathrm{O}$ hydrogen bonds, and $\pi \cdots \pi$ stacking and $\mathrm{C}-\mathrm{H} \cdots \pi$ interaction energies are the most significant forces in the crystal packaging. The estimation of the intermolecular interactions and electrostatic energy values of the complexes are very important for the classification of them for their electrical, magnetic and optical properties.

Keywords: 4-Cyanobenzoate complex, Nicotinamide, $N, N^{\prime}$-Diethylnicotinamide, Hirshfeld surface analysis, Energy Calculations.

Submitted: November 11, 2020. Accepted: December 07, 2020.

Cite this: Öztürkkan F, Sertçelik M, Yüksek M, Necefoğlu H, Hökelek T. Hirshfeld Surface Analysis, Interaction Energy Calculations of Metal (II) 4-Cyanobenzoate with Nicotinamide / N,N'-Diethylnicotinamide Complexes. JOTCSA. 2021;8(1):125-36.

DOI: https://doi.org/10.18596/jotcsa. 824551.

*Corresponding author. E-mail: fozturkkan36@gmail.com. 


\section{INTRODUCTION}

Non-covalent interactions such as hydrogen bonds, halogen bonds, $\mathrm{CH} \cdots \pi$ and $\pi \cdots \pi$ interactions play important roles in chemical, catalytic, photochemical, crystal engineering, and supramolecular processes (1-4). Particularly, hydrogen bonding interactions such as the $\mathrm{O} \cdots \mathrm{H}$ and $\mathrm{N} \cdots \mathrm{H}$ interactions lead to an increase in the stability of crystal packaging (5). Van der Waals interactions also play a key role in the formation of the supramolecular structures. To understand the nature of non-covalent interactions, many theoretical and experimental researches have been carried out in recent years (3). As a new trend, many of studies were done in the field of theoretical chemistry to investigate the structural, physical and biological properties of materials (6). The CrystalExplorer software is a theoretical calculation program that has been widely used in crystallography for the last decade. Hirshfeld surface analysis presents a visual picture and 2D fingerprint plots of crystalline packaging types and intermolecular interactions (7). Thanks to Hirshfeld Surface analysis, by determining a surface, it is possible to partition the electron density of the crystal into molecular parts and to describe the region in which the molecule is located. In this way, the differences among the complexes related to their intermolecular interactions can be determined. With this analysis, both of the contribution of intermolecular interactions to crystal packaging and whether there are the differences at the intermolecular interactions depending on the crystal structures of the complexes can be identified (8). Besides, a new feature has been added to the Crystal Explorer 17.5 software for calculating the pair-wise interaction energies within a crystal. Energy models of the software can be used at the calculations of the interaction energies of neutral organic molecules, organic salts, solvates, coordination compounds, and radicals (9-11). Herein, the Hirshfeld Surface analysis and Interaction Energy Analysis of diaquabis(4cyanobenzoato-kO)bis(nicotinamide-kN1)cobalt(II) (I) (12), diaquabis(4-cyanobenzoato$\kappa O)$ bis(nicotinamide- $\left.k N^{1}\right) \operatorname{copper}($ II) (II) (13) diaquabis(4-cyanobenzoato- $K O$ )bis(nicotinamide$\kappa N^{1}$ )nickel(II) (III) (13), triaqua(4-cyanobenzoato$K^{2} O, O^{\prime}$ )(nicotinamide- $K N$ )zinc(II) 4-cyanobenzoate (IV) (14), diaquabis(4-cyanobenzoato- $K O)$ bis $\left(N, N^{\prime}\right.$ diethylnicotinamide- $K N$ )cadmium(II) (V) (15), diaquabis(4-cyanobenzoato- $K O)$ bis $\left(N, N^{\prime}\right.$ -

diethylnicotinamide- $K N$ )zinc(II) (VI) (16) and catenapoly[[aquabis(4-cyanobenzoato- $K O$ ) copper(II)]- $\mu$ -
$N, N^{\prime}$-diethylnicotinamide- $\left.K^{2} N^{1}: O\right]$

(VII) complexes, which we previously synthesized them and determined their crystal structures, were performed using the CrystalExplorer software. In order to interpret the intermolecular interactions of the complexes, $d_{\text {norm, }}$ shape-index, curvedness, 2D fingerprint, and fragment patches of the molecules were plotted. For the energy frameworks analysis of the complex, electrostatic energy ( $E$ ele), polarization energy (E_pol), dispersion eñergy (E_dis), exchange-repulsion energy (E_rep), and total intermolecular energy (E tot) were calculated using two energy models, which were notified as CEHF/3-21G and CE-B3LYP/6-31G (d,p).

\section{MATERIALS AND METHOD}

Hirshfeld surface analysis $(9,11)$ was performed to investigate the visualization of intermolecular interactions of the complexes that we previously synthesized and characterized (see Figure 1 for the structures) (18). Hirshfeld surface (7, 10), 2D fingerprint (11) plots, and interaction energy analysis were obtained using CrystalExplorer Version 17.5 software based on the input crystallographic information file (CIF) (7). The Tonto Quantum Chemistry package involving in the CrystalExplorer (CE) software was used to achieve more accuracy on intermolecular interactions with energy frame analysis $(8,19,20)$. The intermolecular interaction energies of the complexes were calculated using CE-HF/3-21G and CE-B3LYP/6-31G $(d, p)$ energy models in CrystalExplorer software.

\section{RESULTS AND DISCUSSION}

\section{Hirshfeld Surface Analysis}

Hirshfeld surface analysis, short or long contacts, and intermolecular interactions are visualized by different colors and color intensity (11). The $\mathrm{d}_{\text {norm }}$ maps of the complexes were given in Figure 2. On the $d_{\text {norm }}$ map of the complexes, contacts with a distance shorter than the Van der Waals radii (in close contact) and longer than the Van der Waals radii (in distant contact) were seen as red and blue surfaces, respectively. In addition, distances equal to the sum of the Van der Waals radii were observed as white surfaces (11). 3D Hirshfeld surfaces of the complexes were mapped over $d_{\text {norm }}$ in the range of 0.5248-1.5120 a.u (for I), -0.6299-1.4753 a.u (for II), -0.5207-1.4833 a.u (for III), -0.6210-1.4544 a.u (for IV), -0.6169-1.6478 a.u (for V), -0.5667-1.5939 a.u (for VI) and -0.7415-1,5447 a.u (for VII) (21). 


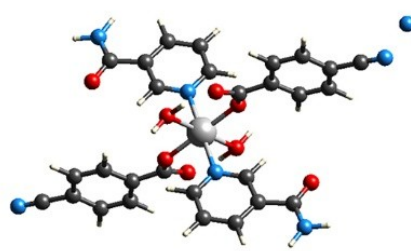

I

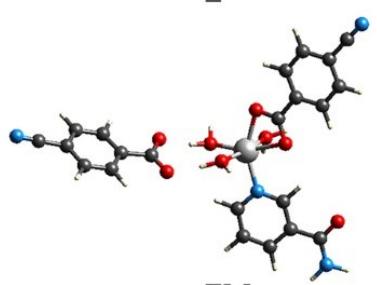

IV

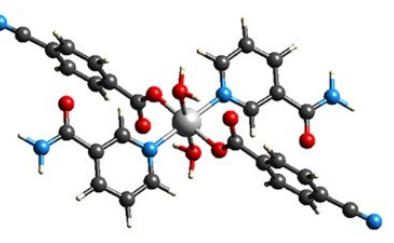

II

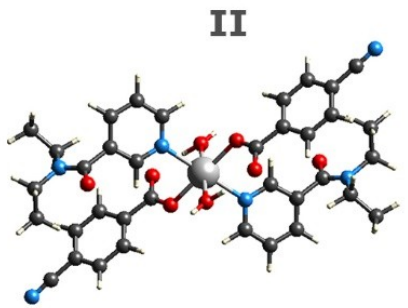

V

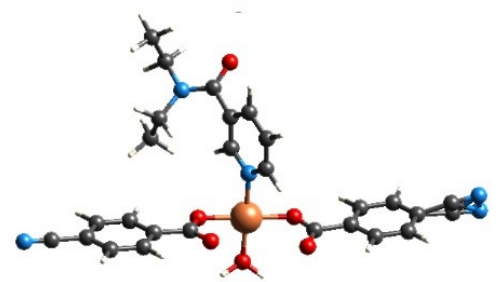

VII

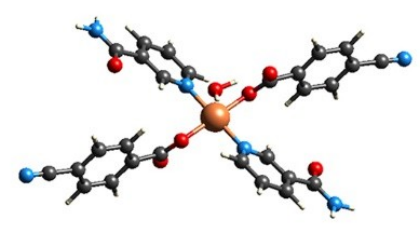

III

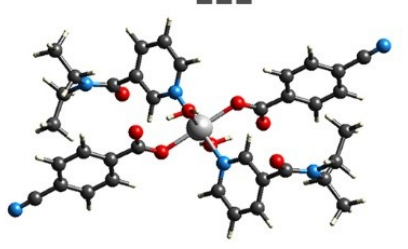

VI

Figure 1. Crystal structure of the complexes.

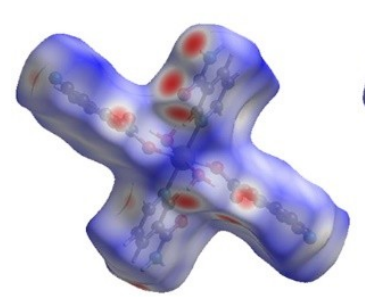

I

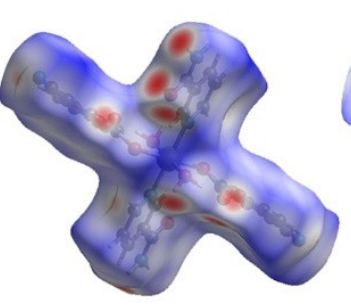

II

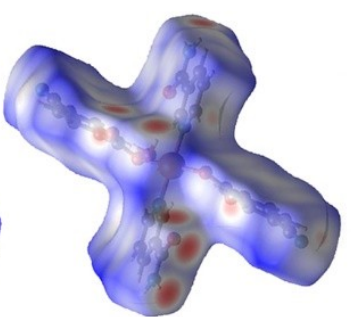

III

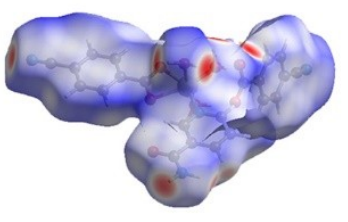

IV

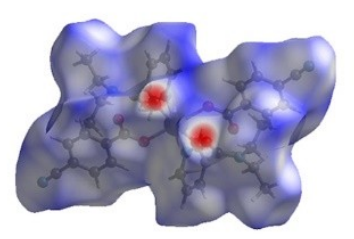

V

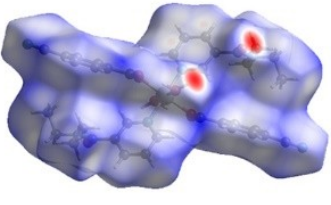

VI

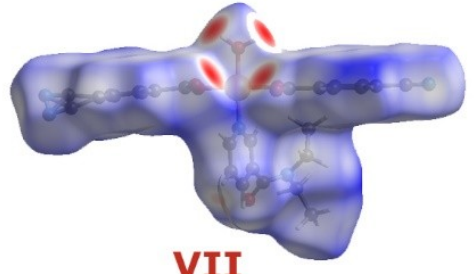

VII

Figure 2. View of the 3D Hirshfeld surfaces of the complexes which were mapped over $d_{\text {norm. }}$.

In the shape indexes of the complexes, the acceptor and donor groups have been represented by red and blue regions, respectively (Figure 3 ). As seen from Figure 3, adjacent red and blue triangles confirm the existence of interactions resulting from $\pi-\pi$ stacking among the aromatic rings in the crystal structures of the complexes (21).

In the Hirshfeld surface analysis of the complexes, in Curvedness maps, relatively large green planes separated by blue edges were observed in the regions where benzene rings of 4-cyanobenzoate ligands and pyridine rings of nicotinamide/ $N, N^{\prime}$ diethylnicotinamide ligands are located. These green planes give us an idea of the flatness of complexes related to $\pi-\pi$ stacking and C...C interactions of the rings. The larger green planes were seen in complex VII with a monoclinic crystal system compared to complexes I-VI that crystallize in the triclinic system (Figure 4) (21). 


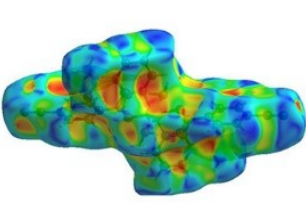

I

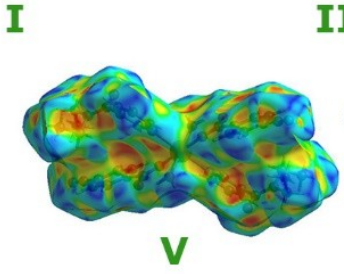

II
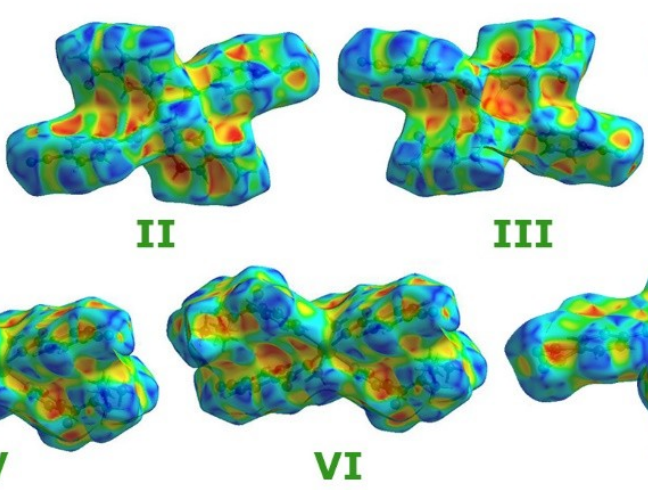

III

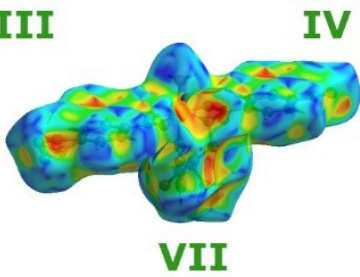

Figure 3. Hirshfeld surface of the complex plotted over shape-index

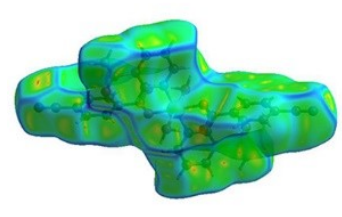

I

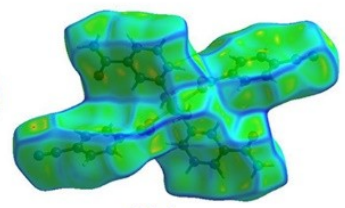

II

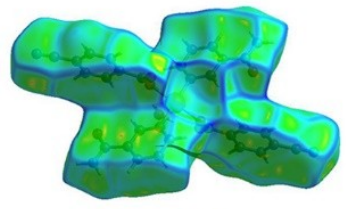

III

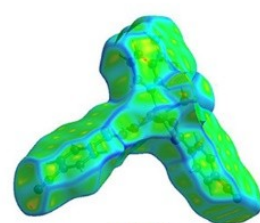

IV

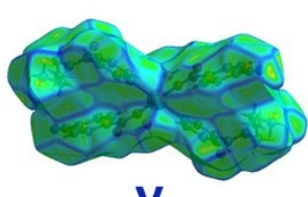

V

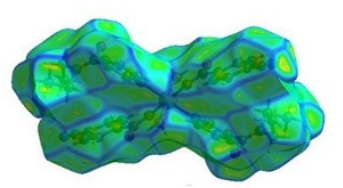

VI

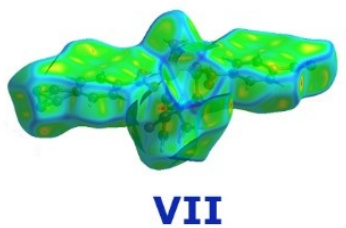

Figure 4. Curvedness maps of the complexes.

2D fingerprint plots for all of the investigated complexes were given in Figure 5. Complexes I, II and III are isostructure. Intermolecular interactions that contribute to the crystal packaging of these three complexes were almost similar (Table 1 ). The main interaction contribution to the stability of these structures were causing by the $\mathrm{H} \cdots \mathrm{C} / \mathrm{C} \cdots \mathrm{H}$ contacts with 27.2 at $\% . \mathrm{H} \cdots \mathrm{H}$ and $\mathrm{H}^{\cdots} \mathrm{O} / \mathrm{O} \cdots \mathrm{H}$ were the second and third major interactions, and they contributed to the interactions by approximately 24.0 at \% and 19 at \%, respectively. According to the crystal structure analysis, $\mathrm{C}-\mathrm{H}^{\cdots} \mathrm{O}$ and $\mathrm{O}-\mathrm{H}^{\cdots} \mathrm{O}$ hydrogen bonds linked the layers together in three dimension networks. As a result, these findings present matchings. The contribution ratios of intermolecular interaction of the three complexes to the crystal package were very close. Differently, only in the complex III, the interactions of $\mathrm{H} \cdots \mathrm{Cu} / \mathrm{Cu} \cdots \mathrm{H}$ and $\mathrm{O} \cdots \mathrm{Cu} / \mathrm{Cu} \cdots \mathrm{O}$ were observed with very small proportion. The most important interaction in complex IV, which was another complex with nicotinamide ligand, whose structure was different from these three complexes, is $\mathrm{H}^{\cdots} \mathrm{H}$ interactions with 32.6 at \%. $\mathrm{H} \cdots \mathrm{O} / \mathrm{O} \cdots \mathrm{H}$ and $\mathrm{H} \cdots \mathrm{N} / \mathrm{N} \cdots \mathrm{H}$ interactions contributed with 20.5 at \% (second important interaction) and with 16.2 at \% (third important interaction) to the intermolecular interactions in complex IV, respectively. These results support the presence of $\mathrm{N}-\mathrm{H} \cdots \mathrm{O}, \mathrm{O}-\mathrm{H} \cdots \mathrm{O}$ hydrogen bonds, which bind molecular components in the crystal structure and make the crystal structure more stable. It was estimated that the $\mathrm{H} \cdots \mathrm{C} / \mathrm{C} \cdots \mathrm{H}$ interactions were the most dominant interaction in the other three complexes containing nicotinamide ligand, and these interactions are the fourth major interaction with 13.3 at \% in complex IV. All of the other interaction percentages that contribute to the crystal architecture were given in Table 1 and plotted in Figures 6 and 7. Although the structures of the three complexes containing $N, N^{\prime}$ diethylnicotinamide ligand were different from each other, the most important intermolecular interactions for all of the three complexes were the $\mathrm{H}$... $\mathrm{H}$ interactions (46.8 at \% (for V), 45.9 at \% (for VI) and 33.2 at \% (for VII). In the complexes 5 and 6 , the second important interactions were the $\mathrm{H} \cdots \mathrm{O} /$ $\mathrm{O} \cdots \mathrm{H}$ interactions with 18.4 at $\%$ and 19.2 at \%, respectively, while the second important interactions in the complex VII were the $\mathrm{H} \cdots \mathrm{N} / \mathrm{N} \cdots \mathrm{H}$ interactions with 19.5 at \%. $\mathrm{H} \cdots \mathrm{N} / \mathrm{N} \cdots \mathrm{H}$ interactions with 15.2 at $\%$ and 15.3 at \% were third important interactions for complex $\mathrm{V}$ and $\mathrm{VI}$, respectively. $\mathrm{H} \cdots \mathrm{C}$ / $\mathrm{C} \cdots \mathrm{H}$ interactions with $16.7 \%$ were third important interactions for complex VII. The fourth important interactions were $\mathrm{H}^{\cdots} \mathrm{C} / \mathrm{C} \cdots \mathrm{H}$ interactions for the complexes $\mathbf{V}$ and $\mathbf{V I}$ and $\mathrm{H} \cdots \mathrm{O} / \mathrm{O} \cdots \mathrm{H}$ interactions for the complex VII. In complex VII, just like complex III, the central atom was copper. Similarly, in the complex VII, $\mathrm{H} \cdots \mathrm{Cu} / \mathrm{Cu} \cdots \mathrm{H}$ and $\mathrm{O} \cdots \mathrm{Cu} / \mathrm{Cu} \cdots \mathrm{O}$ 
interactions were also found. $\mathrm{H} \cdots \mathrm{N} / \mathrm{N} \cdots \mathrm{H}$ and $\mathrm{H} \cdots \mathrm{O} / \mathrm{O} \cdots \mathrm{H}$ interactions confirm the existence of $\mathrm{N}-\mathrm{H} \cdots \mathrm{O}$ and $\mathrm{O}$ $\mathrm{H} \cdots \mathrm{O}$ hydrogen bonds in crystal structures, while
$\mathrm{H} \cdots \mathrm{C} / \mathrm{C} \cdots \mathrm{H}$ interactions support the interaction of benzene and pyridine rings and $\pi-\pi$ stacking for all investigated complexes.

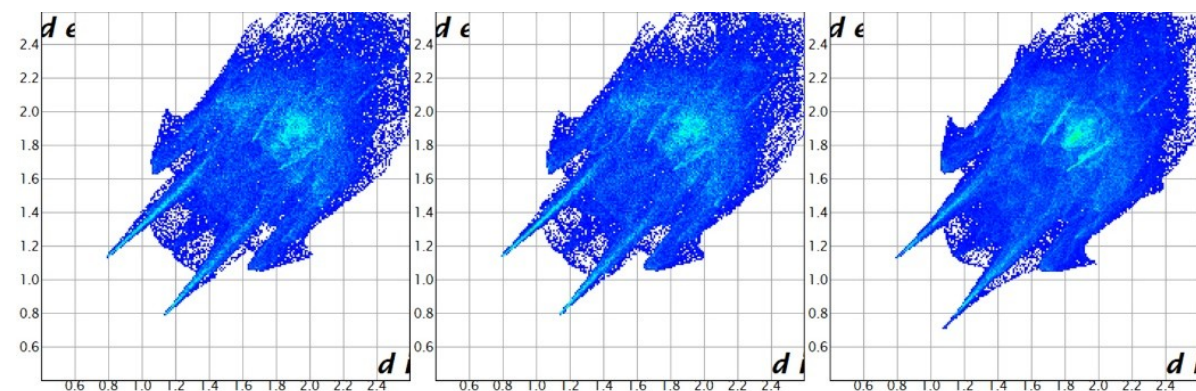

I

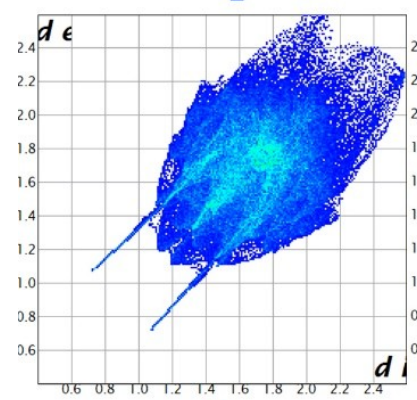

$\mathbf{V}$
II

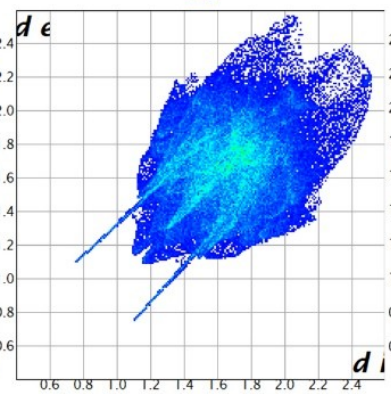

VI

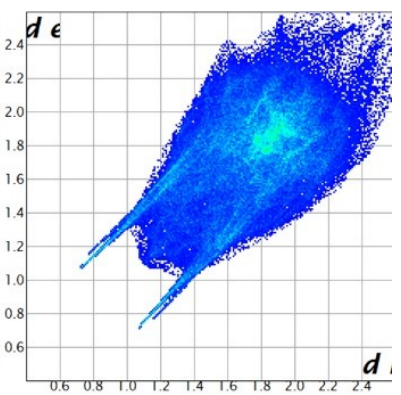

IV

Figure 5. All interactions of two-dimensional fingerprint plots for the complexes I-VII.

Table 1. Intermolecular Interactions of the Complex I-VII.

\begin{tabular}{llllllll}
\hline Interaction & \multicolumn{7}{c}{ Complex } \\
\hline & $\mathbf{I}$ & $\mathbf{I I}$ & $\mathbf{I I I}$ & $\mathbf{I V}$ & $\mathbf{V}$ & $\mathbf{V I}$ & $\mathbf{V I I}$ \\
\hline $\mathbf{H} \cdots \mathbf{O} / \mathbf{O} \cdots \mathbf{H}$ & 18.5 & 20.2 & 18.6 & 20.5 & 18.4 & 19.0 & 16.7 \\
$\mathbf{N} \cdots \mathbf{O} / \mathbf{O} \cdots \mathbf{N}$ & 0.6 & 0.5 & 0.5 & 0.5 & & & 0.2 \\
$\mathbf{C} \cdots \mathbf{O} / \mathbf{O} \cdots \mathbf{C}$ & 1 & 1.1 & 0.9 & 3.4 & 0.2 & 0.2 & 0.6 \\
$\mathbf{H} \cdots \mathbf{H}$ & 25.4 & 23.5 & 25.6 & 32.6 & 46.8 & 45.9 & 33.2 \\
$\mathbf{H} \cdots \mathbf{N} / \mathbf{N} \cdots \mathbf{H}$ & 16.3 & 16.1 & 16.2 & 16.2 & 15.2 & 15.3 & 19.5 \\
$\mathbf{H} \cdots \mathbf{C} / \mathbf{C} \cdots \mathbf{H}$ & 27.2 & 27.4 & 27.1 & 13.3 & 14.3 & 14.7 & 17.7 \\
$\mathbf{N} \cdots \mathbf{N}$ & 2.0 & 1.8 & 1.9 & 0.4 & & & 0.8 \\
$\mathbf{C} \cdots \mathbf{N} / \mathbf{N} \cdots \mathbf{C}$ & 3.6 & 4.1 & 3.8 & 4.4 & 2,3 & 2.2 & 2.7 \\
$\mathbf{C} \cdots \mathbf{C}$ & 5.4 & 4.6 & 5.4 & 8.7 & 2,6 & 2.6 & 6.3 \\
$\mathbf{O} \cdots \mathbf{C u} / \mathbf{C u} \cdots \mathbf{O}$ & & 0.4 & & & & & 1.4 \\
$\mathbf{H} \cdots \mathbf{C u} / \mathbf{C u} \cdots \mathbf{H}$ & & 0.2 & & & & & 0.2 \\
$\mathbf{O} \cdots \mathbf{O}$ & & 0.1 & & & 0,2 & 0.1 & 0.8 \\
\hline
\end{tabular}




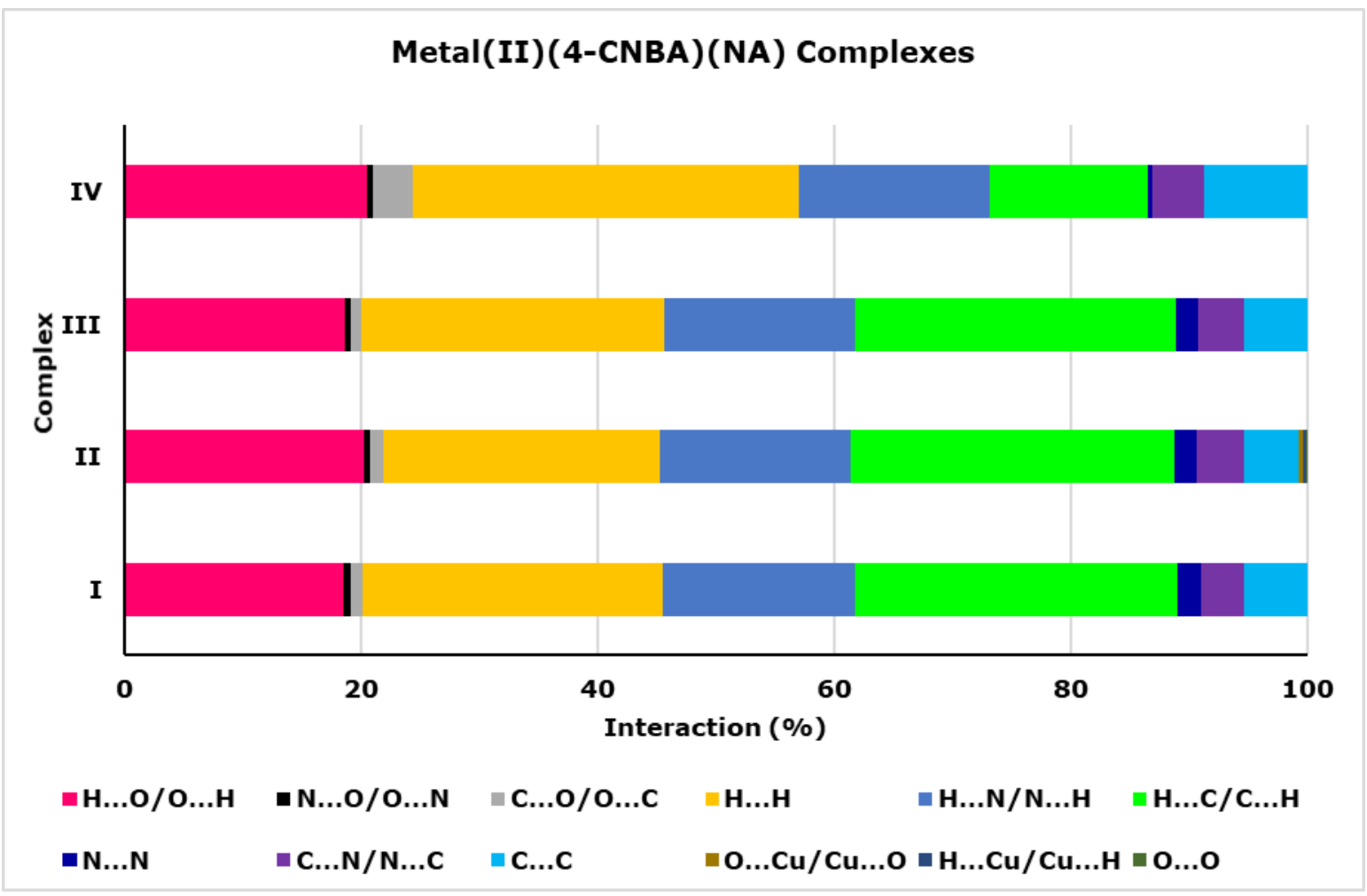

Figure 6. Comparison of the intermolecular interactions of the complex I-IV.

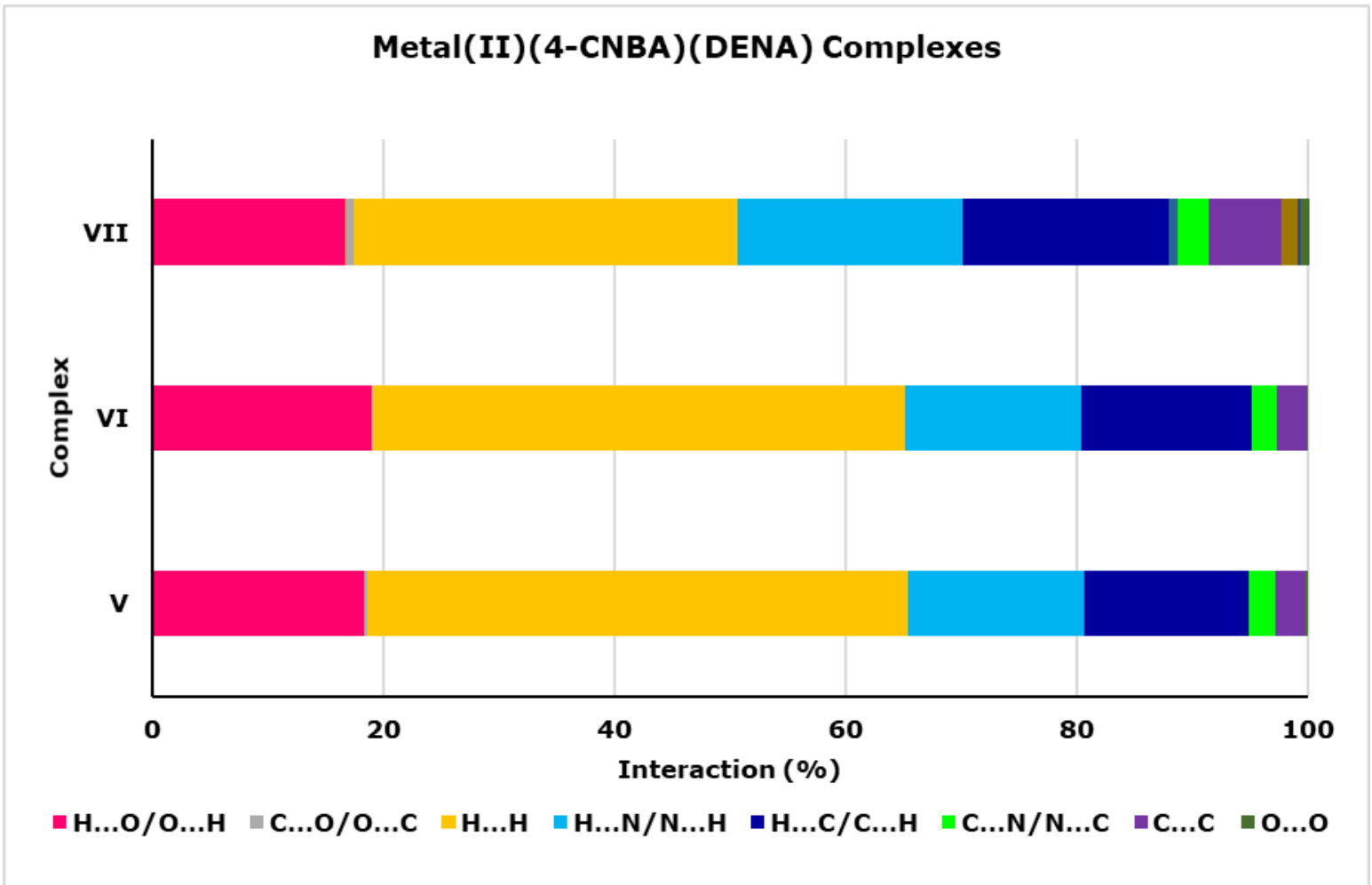

Figure 7. Comparison of the intermolecular interactions of the complex V-VII.

\section{Interactions Energy Analysis}

The total intermolecular energy $\mathrm{E}$ tot $(\mathrm{kJ} / \mathrm{mol})$, which correlative to the reference molecule, is the sum of four main energy component comprising electrostatic (E_ele), polarization (E_pol), dispersion (E dis) and exchange-repulsion (E rep). Scale factors, k_ele, k_pol, k disp, k rep, for B3LYP/6$31 \mathrm{G}(\mathrm{d}, \mathrm{p})$ électron densities and HF/3-21G electron 
densities are used as: $1.057,0.740,0.871$ and 0.618 $\mathrm{kJ} / \mathrm{mol}$ and 1.019, 0.651, 0.901 and $0.811 \mathrm{~kJ} / \mathrm{mol}$, respectively. As seen from Table 3, energy calculations were made by using CE-HF/3-21G, and CE-B3LYP/6-31G(d,p). Two different energy models of the CrystalExplorer software were used to increase the accuracy of the estimation of the energy values. E_tot values of each energy model have shown very similar results in themselves. For complex V, the Tonto Quantum Chemistry package could not calculate the B3LYP/6-31G(d,p) model. It was clearly seen from Table 2 that the dispersion (E_dis), polarization (E_pol) and exchange-repulsion (E rep) and total intermolecular energy ( $E$ tot) values have close for all of the models for isostructural complexes I and III. The total energy values which were calculated for the complex II, which have the same structure as these complexes, are different from those of the I and III complexes. This difference in E_tot value can be attributed to the similarity of the electron configuration of the Co and $\mathrm{Ni}$ central atoms in complexes I and III, respectively. While the values of the two energy models are close to each other for the IV complex, these values are very different from those of the other three complexes which have got nicotinamide ligands. In the VI complexes which involved $N, N^{\prime}$ diethylnicotinamide ligand, the energy values were calculated in both models, and they revealed close values with each other (Table 3 ). The agreement at the values of different models for each molecule can be explained by the stability of the reference molecule. However, these values differ significantly in the VII complex. According to the results of previous studies, we consider that the results of the B3LYP model are more accurate for this complex, which has a polymeric structure. On the other hand, it was determined that electrostatic energy ( $E$ ele) values affect the total energy values. In previous studies, it was reported that the hydrogen bonds contributed to the electrostatic energy. In this study, $\mathrm{N}-\mathrm{H} \cdots \mathrm{O}$ and $\mathrm{O}-\mathrm{H} \cdots \mathrm{O}$ hydrogen bonds and weak $\mathrm{C}-\mathrm{H}^{\cdots} \pi$ interactions significantly contribute to electrostatic energy. Like the structures of the three complexes containing $N, N^{\prime}$-diethylnicotinamide ligand, their energy values are also different from each other $(20,22-24)$.

Table 2. Interaction energy values of the complexes I-IV.

\begin{tabular}{|c|c|c|c|c|c|c|c|c|c|}
\hline & $\mathrm{N}$ & Symop & $R$ & Electron Density & E_ele & E_pol & E_dis & E_rep & E_tot \\
\hline \multirow{12}{*}{ I } & 2 & $x, y, z$ & 13.42 & B3LYP/6-31G(d.p) & -31.6 & -10.7 & -38.3 & 35.8 & -52.6 \\
\hline & 2 & $x, y, z$ & 14.32 & B3LYP/6-31G(d.p) & -69.8 & -17.5 & -21.0 & 66.5 & -64.0 \\
\hline & 2 & $x, y, z$ & 7.65 & B3LYP/6-31G(d.p) & -73.9 & -20.8 & -58.7 & 91.0 & -88.5 \\
\hline & 2 & $x, y, z$ & 10.28 & B3LYP/6-31G(d.p) & -2.8 & -5.8 & -55.2 & 27.1 & -38.6 \\
\hline & 2 & $x, y, z$ & 9.93 & B3LYP/6-31G(d.p) & -67.4 & -28.3 & -82.6 & 87.6 & -110.0 \\
\hline & & & & & -245.5 & -83.1 & -255.8 & 308 & -353.7 \\
\hline & 1 & $x, y, z$ & 13.42 & $\mathrm{HF} / 3-21 \mathrm{G}$ & $\mid-34.4$ & -12.6 & -38.3 & 26.5 & -56.3 \\
\hline & 0 & $x, y, z$ & 14.32 & $\mathrm{HF} / 3-21 \mathrm{G}$ & -66.7 & -20.5 & -21.0 & 48.2 & -61.1 \\
\hline & 1 & $x, y, z$ & 7.65 & $\mathrm{HF} / 3-21 \mathrm{G}$ & -91.3 & -29.3 & -58.7 & 66.6 & -110.9 \\
\hline & 1 & $x, y, z$ & 10.28 & $\mathrm{HF} / 3-21 \mathrm{G}$ & 1.1 & -6.1 & -55.2 & 20.4 & -35.9 \\
\hline & 0 & $x, y, z$ & 9.93 & $\mathrm{HF} / 3-21 \mathrm{G}$ & -73.3 & -35.9 & -82.6 & 68.0 & -117.3 \\
\hline & & & & & -264.6 & $\mid-104.4$ & -255.8 & 229.7 & -381.5 \\
\hline \multirow{2}{*}{ II } & 1 & |- & 2.49 & B3LYP/6-31G(d.p) & $\mid-107.4$ & -30.9 & -21.3 & 118.6 & -81.6 \\
\hline & 1 & - & 2.49 & $\mathrm{HF} / 3-21 \mathrm{G}$ & -106.7 & -44.7 & -21.3 & 77.2 & -94.3 \\
\hline \multirow{7}{*}{ III } & 2 & $x, y, z$ & 7.64 & B3LYP/6-31G(d.p) & -71.0 & -20.4 & -59.8 & 94.3 & -84.0 \\
\hline & 2 & $x, y, z$ & 14.24 & B3LYP/6-31G(d.p) & -70.5 & -17.6 & -21.3 & 64.7 & -66.1 \\
\hline & 2 & $x, y, z$ & 10.25 & B3LYP/6-31G(d.p) & -2.4 & -6.1 & -55.4 & 27.4 & -38.4 \\
\hline & 2 & $x, y, z$ & 9.86 & B3LYP/6-31G(d.p) & -71.4 & -30.8 & -82.9 & 89.6 & -115.1 \\
\hline & 2 & $x, y, z$ & 13.41 & B3LYP/6-31G(d.p) & -32.4 & -11.0 & -38.8 & 35.5 & -54.2 \\
\hline & \multicolumn{4}{|l|}{ Total } & -247.7 & -85.9 & -258.2 & 311.5 & -357.8 \\
\hline & 2 & $x, y, z$ & 7.64 & $\mathrm{HF} / 3-21 \mathrm{G}$ & $\mid-90.6$ & -29.3 & -59.8 & 68.4 & -109.8 \\
\hline
\end{tabular}




\begin{tabular}{|c|c|c|c|c|c|c|c|c|c|}
\hline & 2 & $x, y, z$ & 14.24 & $\mathrm{HF} / 3-21 \mathrm{G}$ & $\mid-67.7$ & -20.5 & -21.3 & 46.7 & -63.7 \\
\hline & 2 & $x, y, z$ & 10.25 & $\mathrm{HF} / 3-21 \mathrm{G}$ & 1.7 & -6.0 & -55.4 & 20.6 & -35.5 \\
\hline & 2 & $x, y, z$ & 9.86 & $\mathrm{HF} / 3-21 \mathrm{G}$ & $\mid-75.1$ & -37.9 & -82.9 & 69.7 & -119.3 \\
\hline & 2 & $x, y, z$ & 13.41 & $\mathrm{HF} / 3-21 \mathrm{G}$ & -34.5 & -12.7 & -38.8 & 26.3 & -57.0 \\
\hline & Total & & & & -266.2 & -106.4 & -258.2 & 231.7 & -385.3 \\
\hline IV & 1 & - & 8.55 & B3LYP/6-31G(d.p) & -94.7 & -15.0 & -13.4 & 181.3 & -11.0 \\
\hline & 1 & - & 8.55 & $\mathrm{HF} / 3-21 \mathrm{G}$ & $\mid-82.7$ & -31.6 & -13.4 & 121.0 & -18.8 \\
\hline
\end{tabular}

E:interaction energies components, Symop: rotational symmetry operations with respect to the reference molecule, R: the centroid-to-centroid distance between the reference molecule $\mathrm{N}$ : interacting molecules as well as the number of pair(s) of interacting molecules with respect to the reference molecule (20).

Table 3. Interaction energy values of the complexes V-VII

\begin{tabular}{|c|c|c|c|c|c|c|c|c|c|}
\hline & $N$ & Symop & $R$ & $\begin{array}{l}\text { Electron } \\
\text { Density }\end{array}$ & E_ele & E_pol & E_dis & E_rep & E_tot \\
\hline & 2 & $x, y, z$ & 7.51 & $\mathrm{HF} / 3-21 \mathrm{G}$ & -47.2 & -16.5 & $\mid-110.3$ & 50.0 & -117.7 \\
\hline & 2 & $x, y, z$ & 8.67 & $\mathrm{HF} / 3-21 \mathrm{G}$ & -28.4 & -10.4 & -111.9 & $\mid 48.4$ & -97.3 \\
\hline V & 2 & $x, y, z$ & $\begin{array}{l}15.3 \\
7\end{array}$ & $\mathrm{HF} / 3-21 \mathrm{G}$ & -0.3 & -1.2 & -9.8 & 1.5 & -8.7 \\
\hline & 2 & $x, y, z$ & 9.86 & $\mathrm{HF} / 3-21 \mathrm{G}$ & -91.4 & -28.1 & -33.3 & 65.7 & -88.1 \\
\hline & 2 & $x, y, z$ & $\begin{array}{l}17.1 \\
6\end{array}$ & $\mathrm{HF} / 3-21 \mathrm{G}$ & -0.2 & -1.6 & -20.4 & 4.3 & -16.1 \\
\hline & & & & & -167.5 & -57.8 & -285.7 & 169.9 & -327.9 \\
\hline \multirow{12}{*}{ VI } & 2 & $x, y, z$ & 7.49 & $\begin{array}{l}\text { B3LYP/6- } \\
\text { 31G(d.p) }\end{array}$ & -41.5 & $\mid-14.3$ & $\mid-112.2$ & 72.7 & -107.2 \\
\hline & 2 & $x, y, z$ & 8.59 & $\begin{array}{l}\text { B3LYP/6- } \\
\text { 31G(d.p) }\end{array}$ & -29.1 & -7.9 & $\mid-112.2$ & 65.1 & -94.1 \\
\hline & 2 & $x, y, z$ & $\begin{array}{l}15.0 \\
7\end{array}$ & $\begin{array}{l}\text { B3LYP/6- } \\
\text { 31G(d.p) }\end{array}$ & 0.1 & -0.9 & -10.7 & 3.0 & -8.1 \\
\hline & 2 & $x, y, z$ & 9.76 & $\begin{array}{l}\text { B3LYP/6- } \\
\text { 31G(d.p) }\end{array}$ & -73.9 & -17.9 & -35.7 & 70.8 & -78.7 \\
\hline & 2 & $x, y, z$ & $\begin{array}{l}16.8 \\
2\end{array}$ & $\begin{array}{l}\text { B3LYP/6- } \\
\text { 31G(d.p) }\end{array}$ & -0.1 & -1.7 & -20.8 & 6.2 & -15.6 \\
\hline & & & & & -144.5 & $\mid-42.7$ & -291.6 & 217.8 & -303.7 \\
\hline & 2 & $x, y, z$ & 7.49 & $\mathrm{HF} / 3-21 \mathrm{G}$ & -45.0 & -16.6 & $\mid-112.2$ & 54.3 & -113.7 \\
\hline & 2 & $x, y, z$ & 8.59 & $\mathrm{HF} / 3-21 \mathrm{G}$ & -29.7 & -9.9 & $\mid-112.2$ & 52.3 & -95.4 \\
\hline & 2 & $x, y, z$ & 15.0 & $\mathrm{HF} / 3-21 \mathrm{G}$ & 0.4 & -1.3 & -10.7 & 2.0 & -8.5 \\
\hline & 2 & $x, y, z$ & 9.76 & $\mathrm{HF} / 3-21 \mathrm{G}$ & -84.7 & -25.6 & -35.7 & 54.1 & -91.2 \\
\hline & 2 & $x, y, z$ & $\begin{array}{l}16.8 \\
2\end{array}$ & $\mathrm{HF} / 3-21 \mathrm{G}$ & 0.3 & -1.6 & -20.8 & 4.6 & -15.8 \\
\hline & \multicolumn{4}{|c|}{ Total } & -158.7 & -55 & -291.6 & 167.3 & -324.6 \\
\hline & 1 & $-x,-y,-z$ & 6.75 & $\begin{array}{l}\text { B3LYP/6- } \\
31 G(d, p)\end{array}$ & $-\overline{554331.1}$ & $\mid-189.8$ & -103.5 & $\mid-3606.6$ & 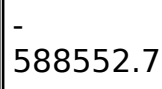 \\
\hline
\end{tabular}




\begin{tabular}{|c|c|c|c|c|c|c|c|c|}
\hline 2 & $\begin{array}{l}-x+1 / 2, y+1 / 2,- \\
z+1 / 2\end{array}$ & 7.40 & $\begin{array}{l}\text { B3LYP/6- } \\
31 G(d, p)\end{array}$ & - & -246.6 & -83.9 & -4100.8 & 471639.7 \\
\hline 2 & $x, y, z$ & $\begin{array}{l}16.6 \\
7\end{array}$ & \begin{tabular}{||l} 
B3LYP/6- \\
$31 G(d, p)$
\end{tabular} & $\begin{array}{l}- \\
357281.4\end{array}$ & -59.7 & -22.7 & 8301.7 & 372689.6 \\
\hline 1 & $\mid-x,-y,-z$ & 7.51 & $\begin{array}{l}\text { B3LYP/6- } \\
31 G(d, p)\end{array}$ & $-\overline{577535.4}$ & -67.8 & -44.5 & $\begin{array}{l}- \\
27937 . \\
6\end{array}$ & $-\overline{6} 27974.2$ \\
\hline 2 & $\begin{array}{l}x+1 / 2,-y+1 / 2 \\
z+1 / 2\end{array}$ & $\begin{array}{l}12.0 \\
4\end{array}$ & \begin{tabular}{||l} 
B3LYP/6- \\
31G(d,p)
\end{tabular} & 343411.2 & -33.3 & -8.0 & -524.5 & 363444.2 \\
\hline 2 & $\begin{array}{l}-x+1 / 2, y+1 / 2,- \\
z+1 / 2\end{array}$ & $\begin{array}{l}14.4 \\
7\end{array}$ & \begin{tabular}{||l} 
B3LYP/6- \\
31G(d,p)
\end{tabular} & -861902.7 & -48.9 & -12.9 & -990.7 & $-\overline{489029.1}$ \\
\hline 2 & $x, y, z$ & $\begin{array}{l}14.6 \\
2\end{array}$ & $\begin{array}{l}\text { B3LYP/6- } \\
31 G(d, p)\end{array}$ & -873681.0 & -68.7 & -14.4 & -1281.6 & - 395947.9 \\
\hline 1 & $\mid-x,-y,-z$ & $\begin{array}{l}13.0 \\
7\end{array}$ & $\begin{array}{l}\text { B3LYP/6- } \\
\text { 31G(d,p) }\end{array}$ & $-\overline{344634.1}$ & -38.8 & -54.8 & -679.6 & $-\overline{364877.9}$ \\
\hline 1 & $\mid-x,-y,-z$ & $\begin{array}{l}16.9 \\
9\end{array}$ & $\begin{array}{l}\text { B3LYP/6- } \\
\text { 31G(d,p) }\end{array}$ & $-\overline{256442.5}$ & -3.0 & -10.8 & -1855.2 & $-\overline{272294.2}$ \\
\hline 2 & $x, y, z$ & 8.02 & $\begin{array}{l}\text { B3LYP/6- } \\
\text { 31G(d,p) }\end{array}$ & -475586.0 & -40.5 & -28.7 & -4542.8 & $-\overline{505698.1}$ \\
\hline \multicolumn{4}{|c|}{ Total } & $\begin{array}{l}- \\
4188247 \\
3\end{array}$ & $-797,1$ & $-384,2$ & $\begin{array}{l}- \\
37217 \\
7\end{array}$ & $\begin{array}{l}- \\
4452147 \\
6\end{array}$ \\
\hline 1 & $\mid-x,-y,-z$ & 6.75 & $\mathrm{HF} / 3-21 \mathrm{G}$ & -297.8 & -100.1 & -103.5 & 235.3 & -271.1 \\
\hline 2 & $\begin{array}{l}-x+1 / 2, y+1 / 2,- \\
z+1 / 2\end{array}$ & 7.40 & $\mathrm{HF} / 3-21 \mathrm{G}$ & -38.1 & -35.3 & -83.9 & 79.2 & -73.1 \\
\hline 2 & $x, y, z$ & $\begin{array}{l}16.6 \\
7\end{array}$ & $\mathrm{HF} / 3-21 \mathrm{G}$ & -1.4 & -7.9 & -22.7 & 10.5 & -18.5 \\
\hline 1 & $\mid-x,-y,-z$ & 7.51 & $\mathrm{HF} / 3-21 \mathrm{G}$ & -40.9 & $\mid-23.6$ & -44.5 & 9.5 & -89.4 \\
\hline 2 & $\begin{array}{l}x+1 / 2,-y+1 / 2 \\
z+1 / 2\end{array}$ & $\begin{array}{l}12.0 \\
4\end{array}$ & $\mathrm{HF} / 3-21 \mathrm{G}$ & 2.6 & -4.0 & -8.0 & 2.4 & -5.2 \\
\hline 2 & $\begin{array}{l}-x+1 / 2, y+1 / 2,- \\
z+1 / 2\end{array}$ & $\begin{array}{l}14.4 \\
7\end{array}$ & $\mathrm{HF} / 3-21 \mathrm{G}$ & 15.2 & -6.2 & -12.9 & 3.1 & 2.4 \\
\hline 2 & $x, y, z$ & $\begin{array}{l}14.6 \\
2\end{array}$ & $\mathrm{HF} / 3-21 \mathrm{G}$ & -3.0 & -4.1 & -14.4 & 2.2 & -17.0 \\
\hline 1 & $-x,-y,-z$ & $\begin{array}{l}13.0 \\
7\end{array}$ & $\mathrm{HF} / 3-21 \mathrm{G}$ & 15.2 & -13.0 & -54.8 & 23.4 & -23.4 \\
\hline 1 & $-x,-y,-z$ & $\begin{array}{l}16.9 \\
9\end{array}$ & $\mathrm{HF} / 3-21 \mathrm{G}$ & 1.1 & -3.3 & -10.8 & 4.3 & -7.3 \\
\hline 2 & $x, y, z$ & 8.02 & $\mathrm{HF} / 3-21 \mathrm{G}$ & 1.5 & -4.7 & -28.7 & 12.8 & -17.0 \\
\hline Total & & & & $-345,6$ & $-202,2$ & $-384,2$ & 382,7 & $-519,6$ \\
\hline
\end{tabular}

E:interaction energies components, Symop: rotational symmetry operations with respect to the reference molecule, R: the centroid-to-centroid distance between the reference molecule $\mathrm{N}$ : interacting molecules as well as the number of pair(s) of interacting molecules with respect to the reference molecule (20). 


\section{CONCLUSION}

In this study, Hirshfeld surfaces and the relationship 2D fingerprint plots of seven complexes, metal(II) 4cyanobenzoate nicotinamide/ $N, N^{\prime}$ diethylnicotinamide, were investigated. According to Hirshfeld Surface Analysis results, $\mathrm{H} \cdots \mathrm{O} / \mathrm{O} \cdots \mathrm{H}, \mathrm{C} \cdots \mathrm{O} / \mathrm{O} \cdots$ $\mathrm{C}, \mathrm{H} \cdots \mathrm{H}, \quad \mathrm{H} \cdots \mathrm{N} / \mathrm{N} \cdots \mathrm{H}, \quad \mathrm{H} \cdots \mathrm{C} / \mathrm{C} \cdots \mathrm{H}, \quad \mathrm{C} \cdots \mathrm{N} / \mathrm{N} \cdots \mathrm{C}$ and $\mathrm{C} \cdots \mathrm{C}$ interactions are found in Hirshfeld surface of all of the complexes. $\mathrm{H} \cdots \mathrm{H}$ interactions provide a significant contribution to the crystal packaging of the complexes. $\mathrm{H} \cdots \mathrm{O} / \mathrm{O} \cdots \mathrm{H}$ and $\mathrm{H} \cdots \mathrm{N} / \mathrm{N} \cdots \mathrm{H}$ interactions also provide a key contribution to the intermolecular interactions of the complexes, and they support the presence of hydrogen bonds in the crystal structures. On the shape-index of the complexes, presences of adjacent red and blue triangles were supported the weak $\mathrm{C}-\mathrm{H} \cdots \pi$ and $\pi-\pi$ stacking interactions between the benzene and pyridine rings in crystal structures. As a result, it can be said that the results obtained from single crystal $X$-ray analysis and Hirshfeld surface analysis have supported each other. The polarization (E_pol), dispersion (E_dis), and exchange-repulsion (E_rep) energies were calculated by using two different models of the CrystalExplorer (CE) software. The E_tot values calculated for I, II, III, IV, VI, and VII complexes with the B3LYP/6-31G(d,p) energy model were found to be $-353.7,81.6,-357.8,-11.0,-303.7$ and $-4452147.6 \mathrm{~kJ} / \mathrm{mol}$, respectively. These values were also calculated for I, II, III, IV, V, VI and VII complexes by using the HF/3-21G energy model, and they were also found to be $-381.5,94.3,-385.3$, $-18.8,-327.9,-324.6$ and $519.6 \mathrm{~kJ} / \mathrm{mol}$, respectively. While the E_tot values of I and III complexes which have similar structures are close to each other in both models, it is thought that the different E_tot values of the complex II, which has isostructural with these complexes, cause by the nature of metal cation. As a result, it was found that the complexes with different structures showed different energy values.

\section{ACKNOWLEDGMENT}

The authors would like to thank Ömer Aydoğdu and Gamze Yılmaz Nayir for their valuable contributions.

\section{REFERENCES}

1. Philp D, Stoddart JF. Self-Assembly in Natural and Unnatural Systems. Angew Chem Int Ed Engl. 1996;35(11):1154-96.

2. Głowacki ED, Irimia-Vladu M, Bauer S, Sariciftci NS. Hydrogen-bonds in molecular solids - from biological systems to organic electronics. J Mater Chem B. 2013;1(31):3742.

3. Seth SK, Manna P, Singh NJ, Mitra M, Jana AD, Das $A$, vd. Molecular architecture using novel types of non-covalent $\pi$-interactions involving aromatic neutrals, aromatic cations and $\pi$-anions. CrystEngComm. 2013;15(7):1285.
4. Martin AD, Britton J, Easun TL, Blake AJ, Lewis W, Schröder M. Hirshfeld Surface Investigation of Structure-Directing Interactions within Dipicolinic Acid Derivatives. Crystal Growth \& Design. 2015;15(4):1697-706.

5. Maity T, Mandal H, Bauzá A, Samanta BC, Frontera A, Seth SK. Quantifying conventional C-H... $\pi($ aryl) and unconventional $\mathrm{C}-\mathrm{H} \cdots \pi$ (chelate) interactions in dinuclear $\mathrm{Cu}(\mathrm{II})$ complexes: experimental observations, Hirshfeld surface and theoretical DFT study. New J Chem. 2018;42(12):10202-13.

6. Kirste B. Applications of Density Functional Theory to Theoretical Organic Chemistry. Chem Sci J. $2016 ; 7(2)$.

7. M. J. Turner, J. J. McKinnon, S. K. Wolff, D. J. Grimwood, P. R. Spackman, D. Jayatilaka and M. A. Spackman, CrystalExplorer17 (2017). University of Western Australia.

8. Tan SL, Jotani MM, Tiekink ERT. Utilizing Hirshfeld surface calculations, non-covalent interaction $(\mathrm{NCl})$ plots and the calculation of interaction energies in the analysis of molecular packing. Acta Crystallogr $\mathrm{E}$ Cryst Commun. 2019;75(3):308-18.

9. Hirshfeld FL. Bonded-atom fragments for describing molecular charge densities. Theoret Chim Acta. 1977;44(2):129-38.

10. McKinnon J, Jayatilaka D, Spackman MA. Towards quantitative analysis of intermolecular interactions with Hirshfeld surfaces. Chem Commun. 2007;(37):3814.

11. Spackman MA, Jayatilaka D. Hirshfeld surface analysis. CrystEngComm. 2009;11(1):19-32.

12. Aşkın GŞ, Necefoğlu H, Yılmaz Nayir G, Çatak Çelik R, Hökelek T. Crystal structure of trans diaquabis(4-cyanobenzoato-k $\mathrm{O}$ )bis(nicotinamide-k N 1 )cobalt(II). Acta Crystallogr E Cryst Commun. 2015;71(5):561-3.

13. Özbek FE, Sertçelik $M$, Yüksek $M$, Necefoğlu $H$, Çelik RÇ, Nayir GY, vd. $\mathrm{Cu}(\mathrm{II})$ and $\mathrm{Ni}(\mathrm{II})$ 4cyanobenzoate complexes with nicotinamide: Synthesis, spectral, structural and optical characterization and thermal behavior. Journal of Molecular Structure. 2017;1150:112-7.

14. Aşkın GŞ, Necefoğlu H, Yılmaz Nayir G, Çatak Çelik R, Hökelek T. Crystal structure of triaqua(4cyanobenzoato-k 20 , $\mathrm{O}^{\prime}$ )(nicotinamide-k $\mathrm{N} 1$ )zinc 4-cyanobenzoate. Acta Crystallogr E Cryst Commun. 2015;71(6):684-6.

15. Akduran N, Sertçelik M, Aydoğdu Ö, Necefoğlu H, Hökelek T. Crystal structure of trans -diaquabis(4cyanobenzoato-k O )bis( N , N -diethylnicotinamide-k 
$\mathrm{N}$ ) cadmium. Acta Crystallogr E Cryst Commun. 2016;72(12):1827-9.

16. Akduran N, Necefoğlu H, Aydoğdu Ö, Hökelek T. Crystal structure of trans -diaquabis(4cyanobenzoato-k O )bis( N , N -diethylnicotinamide- $\mathrm{k}$ $\mathrm{N}$ )zinc(II). Acta Crystallogr $\mathrm{E}$ Cryst Commun. 2016;72(10):1374-6.

17. Akduran N, Necefoğlu H, Aydoğdu Ö, Hökelek T. Crystal structure of catena -poly[[aquabis(4-

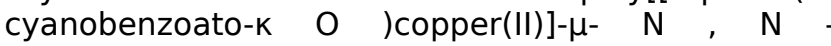
diethylnicotinamide-k $2 \mathrm{~N} \quad 1$ : 0 ]. Acta Crystallographica Section E Crystallographic Communications. 2016;72(8):1183-6.

18. Özbek FE, Sertçelik $M$, Yüksek $M$, Uğurlu $G$, Tonbul AM, Necefoğlu $H$, vd. Synthesis and Crystallographic, Absorption and Emission Studies of 4-Pyridine Carboxamide of $\mathrm{Zn}(\mathrm{II})$ 4Chlorophenylacetate. J Fluoresc. 2019;29(5):126575.

19. Jayatilaka D, Grimwood DJ. Tonto: A Fortran Based Object-Oriented System for Quantum Chemistry and Crystallography. in: Sloot PMA, Abramson D, Bogdanov AV, Gorbachev YE, Dongarra J, Zomaya AY, Eds. Computational Science - ICCS 2003 [Internet]. Berlin, Heidelberg: Springer Berlin Heidelberg; 2003. p. 142-51.
20. Mackenzie CF, Spackman PR, Jayatilaka D, Spackman MA. CrystalExplorer model energies and energy frameworks: extension to metal coordination compounds, organic salts, solvates and open-shell systems. IUCrJ. 2017;4(5):575-87.

21. Spackman MA, McKinnon J, Jayatilaka D. Electrostatic potentials mapped on Hirshfeld surfaces provide direct insight into intermolecular interactions in crystals. CrystEngComm. 2008;10(4):377-88.

22. Caracelli I, Zukerman-Schpector J, Schwab RS, Silva EM da, Jotani MM, Tiekink ERT. 2-Methyl-4-(4nitrophenyl)but-3-yn-2-ol: crystal structure, Hirshfeld surface analysis and computational chemistry study. Acta Crystallogr E Cryst Commun. 2019;75(8):12328.

23. Etse KS, Lamela LC, Zaragoza G, Pirotte B. Synthesis, crystal structure, Hirshfeld surface and interaction energies analysis of 5-methyl-1,3-bis(3nitrobenzyl)pyrimidine-2,4(1H,3H)-dione. Eur J Chem. 2020;11(2):91-9.

24. Madan Kumar S. 3D energy frameworks of dimethylbenzophenone tetramorphs. Heliyon. 2019;5(2):e01209. 
Öztürkkan FE et al. JOTCSA. 2021; 8(1): 125-136.

RESEARCH ARTICLE 